\title{
The Assessment of Land Pollution by Oil Products in the Vicinity of the Operating Oil Pipeline in the Territory of the Sverdlovsk Region
}

\author{
Tamara Simakova ${ }^{1 *}$, Anton Simakov' ${ }^{1}$, Vladimir Tolstov ${ }^{1}$, Leonid Skipin ${ }^{2}$ \\ 1 Federal State Budget Educational Institution of Higher Education, Northern Trans-Ural Agricultural \\ University, Republiki Street 7, 652003 Tyumen, Russia \\ 2 Federal State Budget Educational Institution of Higher Education, Industrial University of Tyumen, \\ Volodarskogo 38, 652000 Tyumen, Russia \\ * Corresponding author's e-mail: simakova.tamara@mail.ru
}

\begin{abstract}
The developing oil and gas industry in the modern world, including the territory of the Russian Federation, does not remain without a trace for the environment. Land is the national wealth of each state, so it is very important to preserve its natural potential and prevent environmental disasters. Accidents at the territories of operating oil pipelines, which cause great harm to all kinds of natural resources - and first of all to land resources- remain unavoidable. The presented research reveals the methodology of the detailed assessment of the level and degree of soil contamination by oil products. The assessment scale was developed and five zones with different degrees of soil contamination by oil products were established. Using the calculation and a graphic method, a map of zones with the degree of contamination was developed and their exact areas were established. The presented development will be used when carrying out land reclamation of the territory under study.
\end{abstract}

Keywords: pollution assessment, petroleum product content, soil sample, degree of contamination, boundaries of the contaminated area, reclamation

\section{INTRODUCTION}

Land resources are a priority among others, as the most important task of each country is to provide people with food. In connection with the long-term restoration of land resources, each state is working with the problem of their rational and efficient use [Simakova et al. 2019, Ryazansteva 2019]. The oil industry is characterized by an intensive impact on the environment, which inevitably causes its change. In the process of production, the existing environmental condition in the areas of industrial facilities is completely or partially violated. These changes are manifested in various combinations of negative phenomena, the most important of which are: the removal of forest land for the placement of objects; depletion and pollution of groundwater and surface water; flooding and waterlogging of the affected areas; dehydration and salinization of soils; pollution by harmful substances and chemical elements of atmospheric air; hydrogeological and geochemical changes unfavorable for local ecological systems. Oil and oil products, as pollutants of subsoil and environment, are evaluated mainly by the degree of toxicity and geochemical stability. When these petroleum products infiltrate into the soil, they move downward under the influence of gravitational forces and spread in breadth under the action of surface and capillary forces. The speed of oil movement depends on its properties, soil properties as well as the ratio of oil, air and water in a multiphase moving system. The oil entering the soil, causes significant and sometimes irreversible changes: hydronization, cementation, etc. [Gaevaya et al. 2019, Pohomova et al. 2016]. 


\section{MATERIAL AND METHODS}

The research was based on the following methods: determination of the spatial coordinates of points of the terrain by satellite geodetic measurements (definitions); graphic method of forming the layers of an electronic plan using the Geographic Information System (GIS) MapInfo Professional 16.0 Windows, in accordance with the symbols for the topographic plans at scales of 1:5000,1:2000,1:1000, 1:500 (Qualifier of conventional signs) [Simakov 2020]; method of soil diagnosis (soil profile method); method of sampling in concentric circles; method of mathematical and graphical modeling [Simakova et al. 2015, Simakova et al. 2018, Evtushkova 2018]. The quantitative chemical analysis of soils was performed in the laboratory, by measuring the mass fraction of oil products in soil and soil samples by using the fluorimetric method [Federal environmental regulatory documents PND F 16.1: 2.21-98. 2013].

\section{RESULTS}

The research was conducted on the territory of the Sosvinskogo District of the Sverdlovsk Region in the area of the operating oil pipeline. Assessment of the state of lands was carried out in the area exposed to an accidental oil spill after cleaning of the territory, in order to make a map of contamination for subsequent reclamation.

In the course of the preparatory stage, in-situ inspection of the territory was established:

1. Area in the district of $1.7 \mathrm{~km}$ from the village of Koshay, Sosvinskogo District of the Sverdlovsk Region, which is part of the Middle Urals taiga district;

2. Boundaries of the polluted area are defined by their location, established by carrying out a set of topographic and geodetic works on the object of research;

3. By visual inspection of the study area 6.07.2021 established:

- territory of the operating oil pipeline has no vegetation cover (disturbed lands), due to the replacement of the top soil layer with infertile soil;

- existing artificial reservoir, located on the northern side of the corridor of the operating oil pipelines, is the lowest place in terms of height, it has clear signs of oil pollution (water color - dark, turbid, on the water surface there is an oil film in places), the coastal area has a dirty and oily color;

- in the northern part of the water body, in the forest area there are local spots of oil products on the soil surface.

On the basis of the results of field surveys, terrain relief, establishment of approximate direction of the territory contamination with oil products in the direction to the north, west and south of the place of oil outlet from the main oil pipeline, the method of sampling by the system of concentric circles was determined, which is used for local soil contamination [Federal environmental regulatory documents GOST 17.4.3.01-2017].

The soils on the territory of the polluted area were studied by sampling according to a certain methodology and using the soil profile method, by laying and describing the soil section (halfsection, ditching). The selected samples were numbered in accordance with the developed numbering (scale). The soil section (half-section, dugouts) was laid on the ground, taking into account the field survey in the area of coordinate points determined by topographic and geodetic works.

Sampling for petroleum products was done with a BP-50 soil drill, at the depth of 0-20 cm, using shovel, glass jars, polyethylene bags and film, with marking the sample code, description of the soil profile (sections, half-sections and dugouts) by morphological features and submitting the samples to the testing laboratory. The samples were taken from the main soil section in five directions (relative to parts of the light) by forming rays at a differentiated distance from the source of contamination.

As a result, five rings were formed up to the southern boundary of the territory of the contaminated area. From the northern part, samples were taken by using the concentric circles method up to the border of the artificial reservoir, as a result 1 point and 5 combined samples were formed at a distance of 40 meters from the main soil section Additional sampling was performed outside the combined samples of the formed rings, taking into account the original scheme of the contaminated land plot borders. In total, more than 100 soil samples were taken in the contaminated area. Background sampling was performed outside the contaminated site from the northeastern part at a 


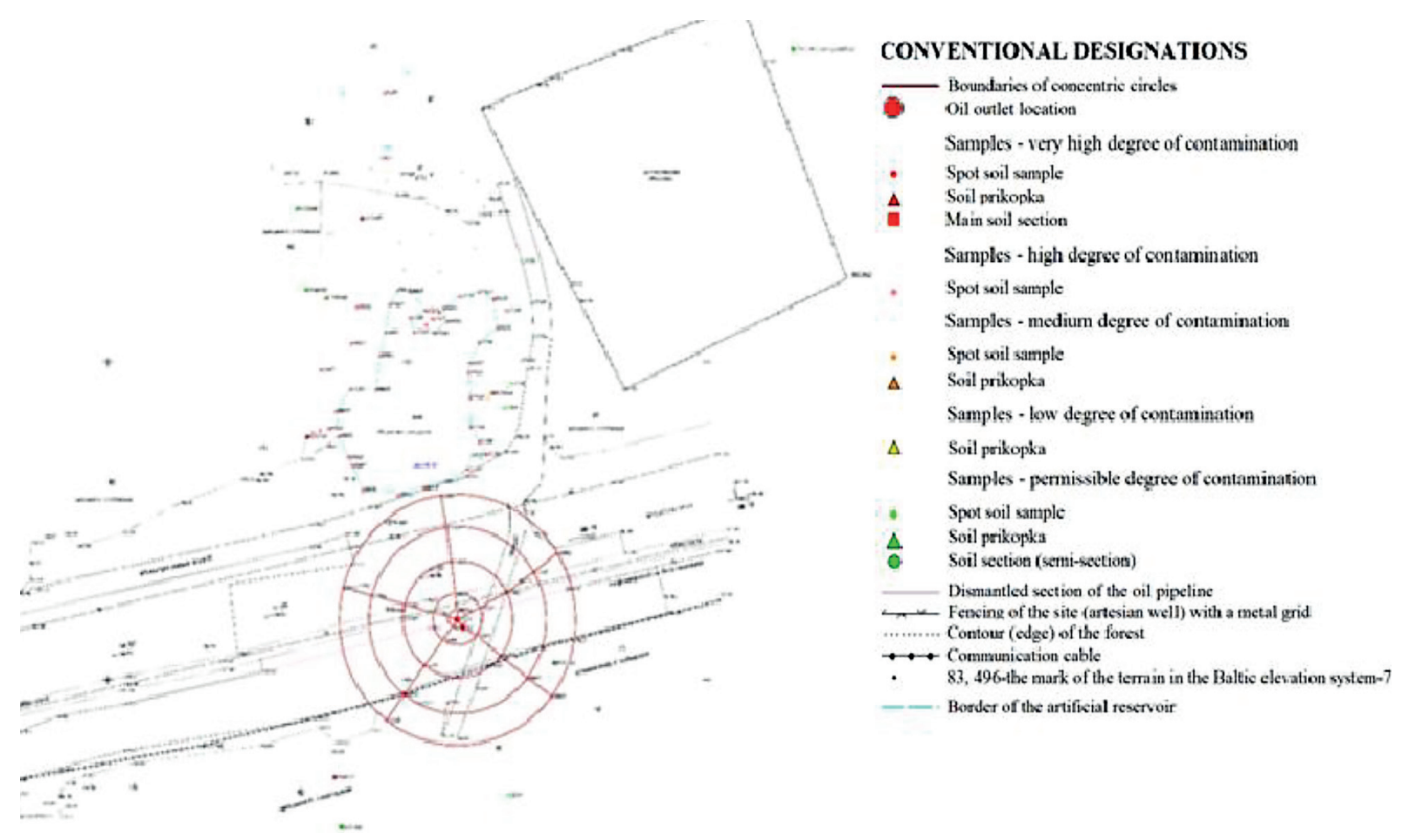

Figure 1. Location of soil sampling

distance of 213 meters. The sampling location is shown in Figure 1.

As a results of soil description on the excavated soil section, half-sections and dugouts it was established that the topsoil is not fertile, is an artificially created horizon at the main section at a depth of $1 \mathrm{~m}$ and in the area of the four dugouts at a depth of $11 \mathrm{~cm}$ to $40 \mathrm{~cm}$. The results of laboratory tests of soil samples are presented in Figure 2.

According to the results of laboratory tests, it was found that 8 out of 43 samples showed acceptable content of oil products in the soil, 1 sample was low, 2 samples were moderate, 3 samples were high and 29 samples were very high. The pollution degree scale (pollution levels

- permissible, low, medium, high, very high) has been defined on the basis of the Letter of the RF Ministry of Environment Protection and Natural Resources dated 27.12.1993 No. 04-25-61-5678 "On the procedure of defining pollution damage from land pollution by chemical substances". Taking into account the content of oil products in the background sample $(32.6 \mathrm{mg} / \mathrm{kg})$, and the results of laboratory testing of the selected soil samples on the territory of the contaminated land plot, the range of the degree of contamination with the following values was determined:
- acceptable level of contamination - the content of petroleum products from $32.6 \mathrm{mg} / \mathrm{kg}$ to $160.0 \mathrm{mg} / \mathrm{kg}$;

- low pollution level - the content of petroleum products from $160.0 \mathrm{mg} / \mathrm{kg}$ to $650.0 \mathrm{mg} / \mathrm{kg}$;

- medium pollution level - content of petroleum products from $650.0 \mathrm{mg} / \mathrm{kg}$ to $975.0 \mathrm{mg} / \mathrm{kg}$; high pollution level - the content of petroleum products from $975.0 \mathrm{mg} / \mathrm{kg}$ to $1630.0 \mathrm{mg} / \mathrm{kg}$;

- very high level of pollution - the content of petroleum products from $1630 \mathrm{mg} / \mathrm{kg}$ and above.

The results of soil description and laboratory tests determined the boundaries of the polluted land plot, taking into account the land category and type of permitted use (Fig. 3).

The areas of contaminated plots on lands of the forest fund subjected to:

- very high degree of pollution

- area No. 1 - $5350 \mathrm{~m}^{2}$;

- area No. 2 - $376 \mathrm{~m}^{2}$;

- high degree of contamination

- area No. 5 - $130 \mathrm{~m}^{2}$;

- medium degree of pollution

- area No. 6 - $136 \mathrm{~m}^{2}$

- low degree of pollution - area No. 9 - $343 \mathrm{~m}^{2}$. 


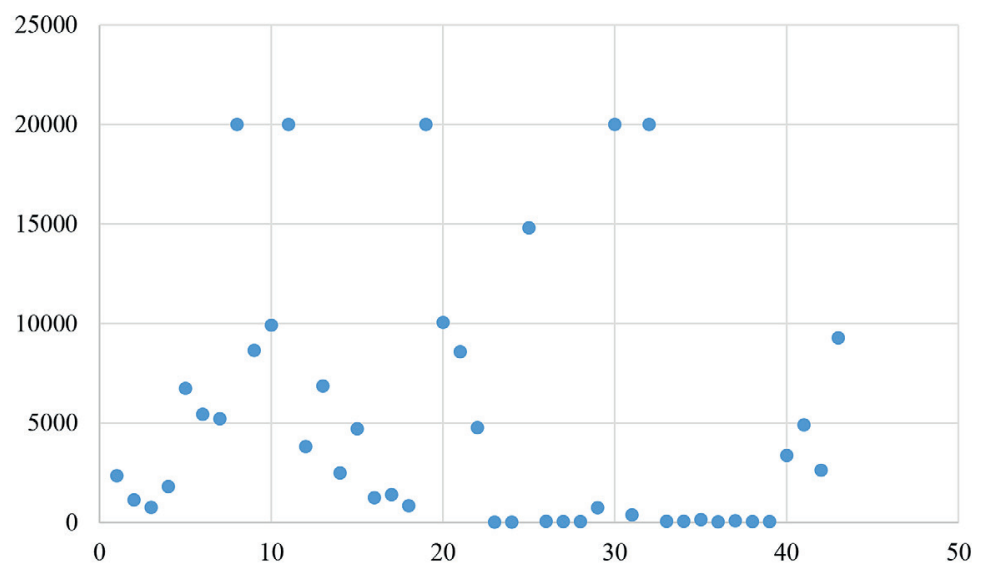

Figure 2. Petroleum products content, $\mathrm{mg} / \mathrm{kg}$
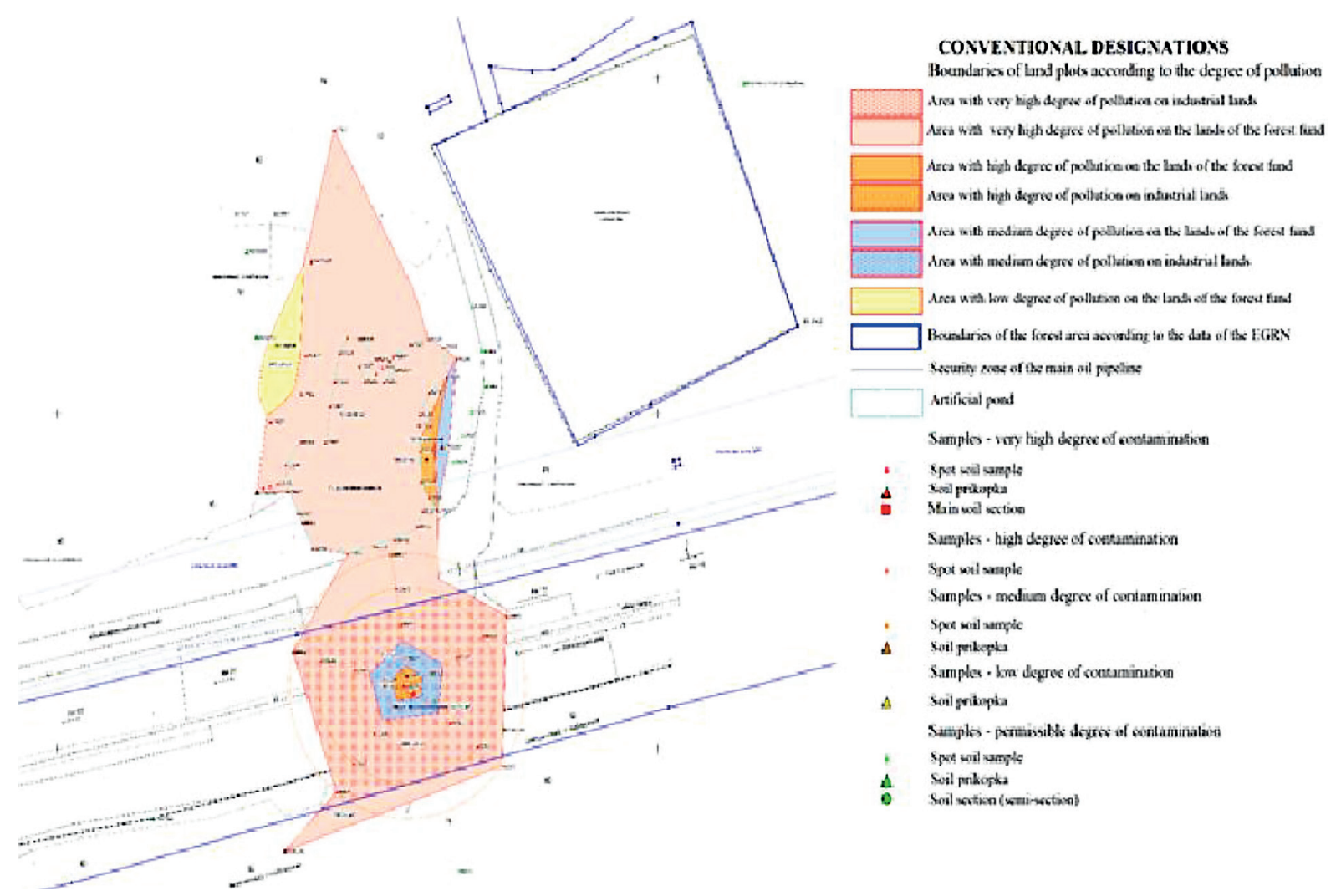

Figure 3. Map of areas with the degree of land pollution by petroleum products

The areas of contaminated sites on industrial land subject to:

- very high degree of pollution

- area No. 3 - $9 \mathrm{~m}^{2}$;

- area No. 8-2896 $\mathrm{m}^{2}$;

- high degree of contamination

- area No. 4-69 $\mathrm{m}^{2}$;

- medium degree of pollution

- area No. 7 - $345 \mathrm{~m}^{2}$.

\section{CONCLUSIONS}

As a result of the assessment of the level of land pollution by petroleum products it was found that the zone with a very high degree of pollution prevails in the study area (the content of petroleum products in the soil more than $1630 \mathrm{mg} / \mathrm{kg})-8631 \mathrm{~m}^{2}$. The zone with a high degree of pollution (the content of petroleum products in the soil from $975.0 \mathrm{mg} / \mathrm{kg}$ 
to $1630.0 \mathrm{mg} / \mathrm{kg}$ ) was $199 \mathrm{~m}^{2}$. For these zones, it is necessary to conduct recultivation in two stages: technological, i.e. cleaning of the contaminated soil layer and application of a clean fertile soil layer and biological, aimed at planting and restoration of plant species peculiar to the current natural and climatic zone. For the areas of medium pollution (oil content in the soil from $650.0 \mathrm{mg} / \mathrm{kg}$ to $975.0 \mathrm{mg} / \mathrm{kg}$ ) area of $481 \mathrm{~m}^{2}$ and a low degree of pollution (oil content in the soil from $160.0 \mathrm{mg} / \mathrm{kg}$ to $650.0 \mathrm{mg} / \mathrm{kg}$ ) area of $343 \mathrm{~m}^{2}$, the biological stage of rehabilitation must be conducted.

\section{REFERENCES}

1. Evtushkova E.P. 2018. Landscape-ecological zoning of natural-territorial complex in the zone of engineering development (on the materials of Sugmutskoye field, Purovsky district, YNAO) / E.P. Evtushkova. Fundamental and applied scientific research: current issues, achievements and innovations: collection of articles of the X International Scientific and Practical Conference. In 2 parts, Penza, March 12, 2018. - Penza: ICSU, Science and Education, 230-233.

2. Federal environmental regulatory documents GOST 17.4.3.01-2017. Interstate standard. Nature Protection. Soils. Methods of sampling and preparation of samples for chemical, bacteriological, helminthological analysis.

3. Federal environmental regulatory documents. 2013. Quantitative chemical analysis of soils. Methodology for measuring the mass fraction of petroleum products in soil and soil samples. 16.1:2.21-98.

4. Simakova T.V., Simakov A.V., Starovoitova E.S., et al. 2019. Formation of a sustainable system is the basis of rational land use managements. Espacios, 40(20), 19.
5. Gaevaya E., Tarasova S., Bytsko A. 2019. Impact of drilling cuttings on the environment and ways of their disposal. Journal of Environmental Engineering, 20(7), 26-30. https://doi. org/10.12911/22998993/109764.

6. Simakova T.V., Skipin L.N., Evtushkova E.P., et al. 2018. Monitoring of reclaimed land in Tyumen region. Espacios, 39(14), 22.

7. Pohomova E.D. 2016. The state of disturbed agricultural lands of the Yamal district of the YNAO/ Pohomova E.D., Simakova T.V., Skipin L.N. Actual issues of science and economy: new challenges and solutions: Proceedings of the L International Student Scientific and Practical Conference, Tyumen, March 17, 2016. Tyumen. Federal State Budgetary Educational Institution of Higher Professional Education. State Agrarian University of Northern Trans-Urals, 700-704.

8. Ryazantseva A.V. 2019.Monitoring of naturalterritorial complex in the zone of oil and gas development (on materials of Bovanenkovo NGKM, Yamal district, YNAO). Collection of theses of VII regional youth conference named after Shpilman V.I. Problems of rational nature management and history of geological prospecting in Western Siberia, Khanty-Mansiysk, March 28-29, 2019. Khanty-Mansiysk. Yugorsky Format. Limited Liability Company, 135-138.

9. Simakova T.V. and Skipin L.N. 2015. The state of land resources on the territory of the federal polygon of the state land monitoring. Nizhnetavdinsky of Tyumen region. Bulletin of KrasSAU, 8(107), 33-37.

10. Simakov A.V. 2020. Development of a map of agricultural land suitability Yarkovsky district, Tyumen region. Innovative development of the agroindustrial complex to ensure food security of the Russian Federation: Proceedings of the International Scientific Conference, Tyumen, December 20, 2021, Tyumen, State Agrarian University of Northern TransUral, 105-113. 